\title{
Pediatric Functional Gastrointestinal Disorders
}

\author{
Mark A. McOmber, MD and Robert J. Shulman, MD \\ Baylor College of Medicine, Houston, Texas
}

\begin{abstract}
Functional gastrointestinal disorders continue to be a prevalent set of conditions faced by the healthcare team and have a significant emotional and economic impact. In this review, the authors highlight some of the common functional disorders seen in pediatric patients (functional dyspepsia, irritable bowel syndrome, functional abdominal pain) as well as one of the more intriguing (cyclic vomiting). The most recent Pediatric Rome Working Group has modified the definitions of functional gastrointestinal disorders. Current studies have used these categorizations to understand better the epidemiology, etiology, and treatment options for these disorders. As more data are available, children and their families will be offered a better understanding of the conditions and more effective treatments to overcome them. The importance of making an accurate diagnosis of a functional gastrointestinal disorder cannot be overemphasized.
\end{abstract}

\section{Keywords}

abdominal pain; gastrointestinal diseases; dyspepsia; irritable bowel syndrome; vomiting

Functional gastrointestinal disorders (FGIDs) are conditions that include a combination of symptoms that are chronic or recurrent and are not explained entirely with current structural or biochemical investigations. The term functional emphasizes that many of the symptoms may accompany normal development (eg, infant regurgitation) or may be a response to otherwise normal internal or external cues (eg, constipation following painful stooling). ${ }^{1}$

Historically, one of the earliest descriptions of a FGID in children was by Apley, ${ }^{2}$ who described a group of children in the community who complained of abdominal pain with no clear etiology that persisted and interfered with daily activities. He coined the phrase recurrent abdominal pain (RAP) to describe this condition. Using Apley's definition, 10\%-17\% of school-aged children have RAP. ${ }^{3-} 10$ Now, however, the term $R A P$ has been modified and subdivided into more defined groups. The most recent revision by the Rome Pediatric Working Group on Functional GI Disorders occurred in $2006 .{ }^{11}$ The process involved group consensus using clinical experience as well as an extensive review of the literature. ${ }^{11}$ The goal of this pediatric working group was to make the criteria more useful for both clinician and researcher, facilitating efforts to make an accurate and definitive diagnosis in these children as well as efforts to provide additional evidence-based data regarding FGIDs in children. ${ }^{11}$ Two studies reviewed the classification of children who previously had been described as having RAP and

(C) 2008 The American Society for Parenteral and Enteral Nutrition. All rights reserved.

Address correspondence to: Robert J. Shulman, MD, 1100 Bates Ave., Houston, TX 77030-2399; rshulman@bcm.tmc.edu..

Financial disclosure: Supported by R01-NR05337, T32-DK07664, P30-DK56338, and the USDA/ARS under Cooperative Agreement No. 6250-51000-043. This work is a publication of the USDA/ARS Children's Nutrition Research Center, Department of Pediatrics, Baylor College of Medicine and Texas Children's Hospital, Houston, TX. The contents of this publication do not necessarily reflect the views or policies of the USDA, nor does mention of trade names, commercial products, or organizations imply endorsement by the U.S. Government. 
divided them into subtypes according to the Pediatric Rome criteria (Table 1).12,13 The majority of these RAP children met the criteria for irritable bowel syndrome $(45 \%)$ or functional dyspepsia (16\%), whereas the third most frequent was functional abdominal pain $(7.5 \%) .{ }^{12}$ Another recent study using prospective methods suggested that $65 \%$ of RAP children had irritable bowel syndrome and 35\% had functional abdominal pain (the latter group may have included some children with functional dyspepsia). 14

In this review, we highlight some of the most common functional disorders seen in pediatric patients (functional dyspepsia, irritable bowel syndrome, functional abdominal pain) as well as one of the more intriguing (cyclic vomiting).

\section{Functional Dyspepsia}

The diagnosis of functional dyspepsia (FD) describes persistent or recurrent pain or discomfort localized to the upper abdomen. ${ }^{11}$ The symptoms commonly occur after eating. Many children miss school because of the pain, nausea, and occasional vomiting attributed to functional dyspepsia. Studies cite a prevalence between 5\% and 16\% in the United States.6.12

Unlike adults, in whom the differential diagnosis is more extensive, in children, cancer of the stomach and esophagus is almost nonexistent, and gastric and duodenal ulcers are much less common. The issue of Helicobacter pylori infection often is raised in individuals with upper GI pain. Although $H$ pylori infection can cause pain as well as ulcers, in children in the United States, $H$ pylori is an uncommon cause of dyspeptic symptoms. ${ }^{15}$

The etiologies of FD have not been fully elucidated. There is some evidence to show that dysmotility may be involved. Abnormal antral contractility was associated with postprandial nausea in some adults with FD. ${ }^{16}$ Adolescents with FD demonstrated delayed gastric emptying and decreased gastric volume accommodation after feeding. ${ }^{17}$ However, in adults, the impaired quality of life did not correlate with delayed gastric emptying. ${ }^{18}$ Psychological factors may play a role in symptom expression. In adults, patients with FD reported higher anxiety and stress than patients with ulcer disease. ${ }^{19}$

There are no specific diagnostic markers for FD, but careful history and physical exam (including evaluation of growth parameters and stool guaiac testing) can determine if additional testing may be required. As with other FGIDs, the presence of so-called red flag symptoms can suggest the need for further testing but should not exclude the diagnostic possibility of a FGID. ${ }^{20}$ Historically, red flags included nocturnal symptoms that awaken the patient, involuntary weight loss, deceleration in linear growth, blood in the stool, fever, urinary complaints, pain away from the umbilicus (especially right lower/upper quadrant), family history of inflammatory bowel disease, and/or organomegaly. Although the presence of these findings may suggest a higher pretest probability of organic disease, the specificity and sensitivity of these findings for organic disease has not been determined in pediatric patients. Indeed, Shulman et al14 observed that children with RAP can present with pain remote from the umbilicus. A systematic review reported that frequency, severity, location, and timing of pain do not distinguish organic from functional abdominal pain.21

Because some studies have suggested abnormalities in motility in patients with FD, ${ }^{16,17}$ some treatments have attempted to enhance gastric emptying. Erythromycin, used frequently to increase and synchronize antral motility, did enhance gastric emptying but was not associated with a beneficial effect on meal-related symptom severity in adults. ${ }^{22}$ Other motility agents have been used in adults with FD. Itopride, a dopamine agonist with antiacetylcholinesterase effects, significantly improves symptoms in adult patients with functional dyspepsia. ${ }^{23}$ Studies in adults suggest that the use of a proton pump inhibitor is associated with improvement in symptoms in some individuals with FD in the absence of gastroesophageal reflux or ulcer 
disease. ${ }^{24}$ Further studies are needed to find medications that could provide benefit to patients with FD, particularly children.

Alternative medicine approaches also are being used for patients with FD. Calvert et $\mathrm{al}^{25}$ showed long-term benefit for patients with FD using hypnotherapy. A recent report demonstrated that acupuncture improves gastric emptying and relieves dyspeptic symptoms in adults with FD and normal gastric emptying. ${ }^{26}$

\section{Irritable Bowel Syndrome}

Irritable bowel syndrome (IBS), as described by the Rome criteria, includes weekly symptoms of abdominal pain or discomfort accompanied by changes in bowel patterns. ${ }^{11}$ These include changes in bowel movement form or frequency at the onset of pain and/or relief of pain with defecation. In adults, the bowel symptoms are used to subclassify the IBS into diarrhea- or constipation-predominant IBS. A systematic review of the literature reported a prevalence of IBS in North American adults between 3\% and 20\%, with most reporting 10\%-15\%.27 Interestingly, this percentage range is similar for pediatric patients with RAP around the world. 28

There appears to be a genetic component to IBS. This appears to be true for RAP as well and presumably IBS in children. IBS tends to "run in families," and mothers of children with RAP are more likely to have a lifetime history of IBS compared with controls. ${ }^{29}$ Concordance for IBS is greater in identical twins than in fraternal twins, highlighting the genetic influence of this disease. ${ }^{30}$

Children and adults with IBS have evidence of visceral hypersensitivity. That is, a stimulus (usually measured in the laboratory as distention of the gut lumen) that does not elicit pain in control individuals will cause pain in an individual with IBS.31 Some of the visceral hypersensitivity appears to stem from a dysregulation in the communication between the enteric nerves of the intestine and the central nervous system.32 Using functional magnetic resonance imaging (MRI) that highlights activity in specific brain regions, studies have demonstrated that altered central nervous system processing of gut signals can play a major role in IBS.33, 34

The visceral hypersensitivity likely is multifactorial. Additional evidence suggests that physiologic stimuli (dietary, gut flora, hormonal), noxious stimuli (inflammation), altered motility, and/or psychological stress may be involved. The visceral hypersensitivity may come from an altered interaction between the gut bacteria and the enteric nervous system. Indeed, it has been demonstrated that the microbiota is significantly altered in adult patients with IBS compared with controls. ${ }^{35}$ In adults (and no doubt in children), IBS may develop after an enteric viral, bacterial, or parasitic infection.36,37 Despite resolution of the infection, the symptoms of IBS can persist for years. 37 It has been suggested that this so-called postinfectious IBS may be responsible for up to $30 \%$ of cases in adults. 38 Along these lines, some patients with IBS have demonstrated increased proinflammatory cytokines, suggesting that intestinal inflammation may play a role in IBS symptoms. ${ }^{39}$ One particular type of inflammatory cell that has been studied in IBS is the mast cell, also involved in histamine reactions in allergic diseases. In animal studies, these cells can excite gut sensory nerves, leading to symptoms similar to IBS in humans. ${ }^{40}$ Adults with diarrhea-predominant IBS have been noted to have a marked increase of mast cells in their small intestine. ${ }^{41}$ What role inflammation plays in the etiology of IBS symptoms in children requires further study.

Another important factor is the psychological component. The way children handle stressors may contribute to the development or expression of FGIDs, including IBS. Adults with high levels of stress and anxiety are more likely to develop IBS after a GI infection. ${ }^{42}$ Other studies 
have demonstrated that the way children handle their stressors may predispose them to FGID symptoms. For example, children with RAP were more likely to use less effective coping strategies to handle stress than control children. ${ }^{43}$ In fact, the use of less effective coping skills also was associated with depressive symptoms, which may accompany many of the FGIDs. ${ }^{44}$

Treatments for IBS have targeted the possible causes of the visceral hypersensitivity, including the potential role of small intestinal bacterial overgrowth. Pimentel et $\mathrm{al}^{45}$ demonstrated in adults that the nonabsorbed oral antibiotic rifaximin can improve IBS symptoms. In addition, peppermint oil, a smooth muscle relaxant that also has antimicrobial properties, was effective in reducing severity of pain associated with IBS in children. ${ }^{46}$ Probiotics, bacteria designed to repopulate the gut and possibly demonstrate anti-inflammatory effects, have been evaluated as treatments for IBS symptoms. In children and adults, the modest benefits appear to be species specific, ${ }^{47-49}$ and further studies are awaited to establish the exact role that probiotics can play in treating IBS.

Serotonin, a hormone involved in gut motility, also has been targeted for treatment of IBS patients. Two examples include the serotonin receptor agonist tegaserod (recently taken off the market due to adverse side effects) used to treat constipation-predominant IBS, and the serotonin receptor antagonist alosetron, which is available on a restricted-use basis (again because of side effects) to treat diarrhea-predominant IBS. Another more central approach involves the selective serotonin reuptake inhibitor (SSRI) citalopram. In adults, citalopram was shown to improve IBS symptoms (but with less effect on stool pattern) compared with placebo. This effect was independent of its effect on anxiety or depression. ${ }^{50}$ Similar benefits also were seen with citalopram in children with functional abdominal pain.51

The hormone melatonin also reduced IBS pain symptoms in adults, independent of its effect on sleep or psychological profiles when compared with placebo. ${ }^{52}$ The tricyclic antidepressant amitriptyline was shown to reduce brain activation during pain, especially during stress, suggesting a potential role in blunting pain and symptoms caused by stress in IBS. ${ }^{53}$ Whether these treatments will be effective in children has yet to be elucidated, but studies are under way.

Fiber supplementation has proven beneficial in 1 double-blind, placebo-controlled trial in children with recurrent abdominal pain. ${ }^{54}$ Further studies are anticipated to determine the benefit of fiber treatment in children with IBS.

\section{Functional Abdominal Pain}

According to the Rome criteria, functional abdominal pain (FAP) is characterized by weekly abdominal pain lasting at least 2 months. ${ }^{11}$ It is distinguished from FD by the location of pain and from IBS by the lack of bowel symptoms. When the pain interferes with activities or is accompanied by other somatic symptoms (eg, headache, sleeping disturbance, extremity pain, or dizziness), it is labeled as functional abdominal pain syndrome (FAPS). A systematic review of the literature using the search criterion recurrent abdominal pain (the term that includes functional abdominal pain) found the prevalence in children of Western countries to range from $0.3 \%$ to $19 \%$, with a median of $8.4 \%$. The highest prevalence was in women and children older than age 4 years to adolescence. ${ }^{55}$

As with IBS, children with FAP appear to have an underlying visceral hypersensitivity. For example, children with IBS and FAP have increased rectal sensitivity compared with controls. In addition, these children have abnormal pain referral after rectal distension, suggesting modified pain receptors and/or interpretation. ${ }^{31}$ DiLorenzo et al ${ }^{56}$ demonstrated that sites of visceral hyperalgesia can differentiate FAP and IBS; IBS patients demonstrate more rectal 
hypersensitivity than children with FAP, and FAP patients demonstrate more gastric hypersensitivity than IBS patients.

Caring for children with FAP can be difficult for both the parent and the physician. Many parents provide extra attention to their children in hope of ameliorating the pain. In a study by Walker et al, ${ }^{57}$ children with abdominal pain underwent water load testing (the children drank a volume of water that caused less intense but representative abdominal pain), and parents were randomly assigned to provide either attention to the pain with reassurance and sympathy or distraction away from the pain. The parents of children with abdominal pain rated that "distraction" would have a greater negative impact on their child than "attention." Surprisingly, the children in the distraction group rated their parents as making them feel better compared with those from the attention group.

The treatments aimed at treating the abdominal pain in IBS also are used for patients with FAP (see above). Complementary medical approaches also have been used. Gut-directed hypnotherapy is highly effective in the treatment of children with longstanding FAP or IBS, demonstrating reduction in pain scores when compared with medical therapy ${ }^{58}$ Combination therapy with psychological treatment (ie, cognitive behavioral therapy) combined with medical treatment appears to be the most effective for helping children overcome these FGIDs.59

\section{Cyclic Vomiting Syndrome}

Although cyclic vomiting syndrome (CVS) is not a very prevalent diagnosis (1\%-3\%), it merits special attention for its unique characteristics and predilection for children. ${ }^{60}, 61$ The Rome criteria describe a recurrent period of intense nausea and unremitting vomiting over hours to days separated by symptom-free intervals lasting weeks to months. 1 In a study that characterized the clinical features of CVS, the peak intensity of vomiting was $\geq 4 /$ hour, but the frequency of episodes was $\leq 9 /$ month. 62

The episodes often escalate rapidly and often terminate as abruptly as they started. It appears to be more prevalent in children than adults, especially children ages 2-7 years old, although the prevalence for adults is not well described. ${ }^{63}$

Accompanying symptoms can include headache, phonophobia, photophobia, fever, loose stools, skin blotching, and leukocytosis. Given these associations, it should come as no surprise that many of these children have other pain syndromes, particularly migraine headaches $(11 \%)$ 64 and IBS (62\%).65 In fact, family histories of IBS and/or migraine headaches are common. A recent study confirmed that patients with CVS, their mothers, and their grandmothers had twice the prevalence of migraine headaches compared with controls. 66

Similar to migraines, many of these children are able to identify circumstances that trigger the vomiting episodes. These can include anxiety, excitement, infections, or physical exhaustion. ${ }^{67}$ Despite the identification, these triggers are often difficult to avoid.

The symptoms can lead some to pursue a path of investigation that can be costly in both time and money for the patients. This can include tests to exclude intracranial neoplasia, vestibulitis, obstructive uropathy, gastrointestinal obstruction, recurrent pancreatitis, metabolic and endocrine disease, and/or familial dysautonomia. ${ }^{68}$ It is important to keep CVS on the differential when evaluating a child with recurrent vomiting episodes as recognition of the pattern will allow for earlier treatment of the disease and family relief.

Cyclic vomiting syndrome is related to repeated activation of the vomiting reflex. The vomiting reflex is associated with 2 centers in the brain, the chemoreceptor trigger zone and the central vomiting center. These centers receive input from visceral afferents as well as higher centers 
(thalamus, hypothalamus, inner ear, cerebral cortex). The input may include visceral, olfactory, or vestibular stimuli or stress interpretation. If the input to the vomiting center exceeds a certain threshold, the vomiting process is initiated with preejection autonomic activation (salivation, pallor, headache, nausea, etc). In many CVS patients, this autonomic activation can be intense with release of corticotropin, vasopressin, norepinephrine, and prostaglandin F. After this preejection phase, the ejection phase follows with repeated vomiting and retching. ${ }^{63}$

The cause of CVS is not completely understood. Given the prevalence of maternal migraine headaches, studies have investigated the possible role of mitochondrial deoxyribonucleic acid (mtDNA) mutations.61,69 The study by Wang et al69 found differences in mtDNA sequences in children with CVS as well as migraine without aura (the headache type commonly associated with CVS) when compared with control children. They suggested that this mitochondrial component to the disease may imply that avoidance of fasting could prove helpful in these children.

The treatment for CVS involves a dual approach of abortive and preventive therapy depending on the severity of symptoms. The preventive approach includes tricyclic antidepressants (amitriptyline), cyproheptadine, phenobarbital, or propranolol. These medications decrease the sensitivity of the chemoreceptor trigger zone in the brain medulla that is partially responsible for the vomiting episodes. They have been shown to reduce or eliminate the vomiting episodes in many children with $\mathrm{CVS}^{70-}{ }^{-72}$

Abortive therapy is best administered during the preceding prodrome before the nausea and vomiting start. Ondansetron, erythromycin, and ibuprofen also have been used. With the vomiting, an acid-blocking agent can help protect the esophagus and teeth but does not affect the symptoms. Lorazepam, an anxiolytic/sedative, also acts as an antiemetic and can be helpful early in the course. For some, intravenous fluids and treatment are needed. Intravenous combinations of ondansetron, granisetron, diphenhydramine, and chlorpromazine may be effective. ${ }^{63,73}$

Considering the extensive and often expensive diagnostic workup that many patients with FGIDs can receive, Olson and $\mathrm{Li}^{74}$ looked at the cost-effectiveness of different diagnostic and treatment options for CVS. They compared empiric treatment alone, upper GI radiographic series with small bowel follow-through, and empiric treatment vs extensive diagnostic evaluation. They found that this GI radiographic imaging modality plus empiric migraine therapy was the most cost-effective strategy for treating CVS. The cost of adding the GI radiographic imaging was less than the cost of complications from missing a GI obstruction.

\section{Summary}

FGIDs are a cause of great distress and morbidity in children and adults. We have learned a lot since Apley's description of "recurrent abdominal pain" was published. As more data are available, we will offer these children and their families a better understanding of the conditions and more effective treatments to overcome them. The importance of making a positive diagnosis of a FGID cannot be overstressed. Children and their parents need to understand that they have a medical diagnosis and not one that is solely psychologically based. Management and treatment must take into account the physiological and psychological contributions to symptom expression.

\section{References}

1. Hyman PE, Milla PJ, Benninga MA, Davidson GP, Fleisher DF, Taminiau J. Childhood functional gastrointestinal disorders: neonate/toddler. Gastroenterology 2006;130:1519-1526. [PubMed: 16678565] 
2. Apley J. Recurrent abdominal pains: a field survey of 1,000 school children. Arch Dis Child 1958;33:165-170. [PubMed: 13534750]

3. Apley, J. The Child With Abdominal Pains. Blackwell Scientific; London: 1975.

4. Arnhold RG, Callos ER. Composition of a suburban pediatric office practice: an analysis of patient visits during one year. Clin Pediatr 1966;5:722-727.

5. Hyams JS, Treem WR, Justinich CJ, Davis P, Shoup M, Burke G. Characterization of symptoms in children with recurrent abdominal pain: resemblance to irritable bowel syndrome. J Pediatr Gastroenterol Nutr 1995;20:209-214. [PubMed: 7714688]

6. Hyams JS, Burke G, Davis PM, Rzepski B, Andrulonis PA. Abdominal pain and irritable bowel syndrome in adolescents: a community-based study. J Pediatr 1996;129:220-226. [PubMed: 8765619]

7. Hyams JS. Recurrent abdominal pain and irritable bowel syndrome in children. J Pediatr Gastroenterol Nutr 1997;25(suppl 1):S16-S17. [PubMed: 9285855]

8. Hyams JS, Hyman PE. Recurrent abdominal pain and the biopsychosocial model of medical practice. J Pediatr 1998;133:473-478. [PubMed: 9787683]

9. Levine MD, Rappaport LA. Recurrent abdominal pain in school children: the loneliness of the longdistance physician. Pediatr Clin North Am 1984;31:969-991. [PubMed: 6384903]

10. Zuckerman B, Stevenson J, Bailey V. Stomachaches and headaches in a community sample of preschool children. Pediatrics 1987;79:677-682. [PubMed: 3575021]

11. Rasquin A, Di LC, Forbes D, et al. Childhood functional gastrointestinal disorders: child/adolescent. Gastroenterology 2006;130:1527-1537. [PubMed: 16678566]

12. Walker LS, Lipani TA, Greene JW, et al. Recurrent abdominal pain: symptom subtypes based on the Rome II Criteria for pediatric functional gastrointestinal disorders. J Pediatr Gastroenterol Nutr 2004;38:187-191. [PubMed: 14734882]

13. Caplan A, Walker L, Rasquin A. Validation of the pediatric Rome II criteria for functional gastrointestinal disorders using the questionnaire on pediatric gastrointestinal symptoms. J Pediatr Gastroenterol Nutr 2005;41:305-316. [PubMed: 16131985]

14. Shulman RJ, Eakin MN, Jarrett M, Czyzewski DI, Zeltzer LK. Characteristics of pain and stooling in children with recurrent abdominal pain. J Pediatr Gastroenterol Nutr 2007;44:203-208. [PubMed: 17255832]

15. Gold BD, Colletti RB, Abbott M, et al. Helicobacter pylori infection in children: recommendations for diagnosis and treatment. J Pediatr Gastroenterol Nutr 2000;31:490-497. [PubMed: 11144432]

16. Troncon LE, Herculano JR Jr, Savoldelli RD, Moraes ER, Secaf M, Oliveira RB. Relationships between intragastric food maldistribution, disturbances of antral contractility, and symptoms in functional dyspepsia. Dig Dis Sci 2006;51:517-526. [PubMed: 16614961]

17. Chitkara DK, Camilleri M, Zinsmeister AR, et al. Gastric sensory and motor dysfunction in adolescents with functional dyspepsia. J Pediatr 2005;146:500-505. [PubMed: 15812453]

18. Talley NJ, Locke GR III, Lahr BD, et al. Functional dyspepsia, delayed gastric emptying, and impaired quality of life. Gut 2006;55:933-939. [PubMed: 16322108]

19. Nakao H, Konishi H, Mitsufuji S, et al. Comparison of clinical features and patient background in functional dyspepsia and peptic ulcer. Dig Dis Sci 2007;52:2152-2158. [PubMed: 17420943]

20. Whitehead WE, Palsson OS, Feld AD, et al. Utility of red flag symptom exclusions in the diagnosis of irritable bowel syndrome. Aliment Pharmacol Ther 2006;24:137-146. [PubMed: 16803612]

21. American Academy of Pediatrics Subcommittee on Chronic Abdominal Pain. Chronic abdominal pain in children. Pediatrics 2005;115:e370-e381. [PubMed: 15741363]

22. Arts J, Caenepeel P, Verbeke K, Tack J. Influence of erythromycin on gastric emptying and meal related symptoms in functional dyspepsia with delayed gastric emptying. Gut 2005;54:455-460. [PubMed: 15753526]

23. Holtmann G, Talley NJ, Liebregts T, Adam B, Parow C. A placebo-controlled trial of itopride in functional dyspepsia. N Engl J Med 2006;354:832-840. [PubMed: 16495395]

24. Moayyedi P, Delaney BC, Vakil N, Forman D, Talley NJ. The efficacy of proton pump inhibitors in nonulcer dyspepsia: a systematic review and economic analysis. Gastroenterology 2004;127:1329_ 1337. [PubMed: 15521002] 
25. Calvert EL, Houghton LA, Cooper P, Morris J, Whorwell PJ. Long-term improvement in functional dyspepsia using hypnotherapy. Gastroenterology 2002;123:1778-1785. [PubMed: 12454833]

26. Xu S, Hou X, Zha H, Gao Z, Zhang Y, Chen JD. Electroacupuncture accelerates solid gastric emptying and improves dyspeptic symptoms in patients with functional dyspepsia. Dig Dis Sci 2006;51:21542159. [PubMed: 17082991]

27. Saito YA, Schoenfeld P, Locke GR III. The epidemiology of irritable bowel syndrome in North America: a systematic review. Am J Gastroenterol 2002;97:1910-1915. [PubMed: 12190153]

28. Dong L, Dingguo L, Xiaoxing X, Hanming L. An epidemiologic study of irritable bowel syndrome in adolescents and children in China: a school-based study. Pediatrics 2005;116:e393-e396. [PubMed: 16140684]

29. Campo JV, Bridge J, Lucas A, et al. Physical and emotional health of mothers of youth with functional abdominal pain. Arch Pediatr Adolesc Med 2007;161:131-137. [PubMed: 17283297]

30. Bengtson MB, Ronning T, Vatn MH, Harris JR. Irritable bowel syndrome in twins: genes and environment. Gut 2006;55:1754-1759. [PubMed: 17008364]

31. Faure C, Wieckowska A. Somatic referral of visceral sensations and rectal sensory threshold for pain in children with functional gastrointestinal disorders. J Pediatr 2007;150:66-71. [PubMed: 17188617]

32. Di LC, Colletti RB, Lehmann HP, et al. Chronic abdominal pain in children: a clinical report of the American Academy of Pediatrics and the North American Society for Pediatric Gastroenterology, Hepatology and Nutrition. J Pediatr Gastroenterol Nutr 2005;40:245-248. [PubMed: 15735475]

33. Lawal A, Kern M, Sidhu H, Hofmann C, Shaker R. Novel evidence for hypersensitivity of visceral sensory neural circuitry in irritable bowel syndrome patients. Gastroenterology 2006;130:26-33. [PubMed: 16401465]

34. Naliboff BD, Berman S, Suyenobu B, et al. Longitudinal change in perceptual and brain activation response to visceral stimuli in irritable bowel syndrome patients. Gastroenterology 2006;131:352365. [PubMed: 16890589]

35. Kassinen A, Krogius-Kurikka L, Makivuokko H, et al. The fecal microbiota of irritable bowel syndrome patients differs significantly from that of healthy subjects. Gastroenterology 2007;133:2433. [PubMed: 17631127]

36. Gomez-Escudero O, Schmulson-Wasserman MJ, Valdovinos-Diaz MA. Post-infectious irritable bowel syndrome. A review based on current evidence [article in Spanish]. Rev Gastroenterol Mex 2003;68:55-61. [PubMed: 12940101]

37. Mearin F, Perez-Oliveras M, Perello A, et al. Dyspepsia and irritable bowel syndrome after a Salmonella gastroenteritis outbreak: one-year follow-up cohort study. Gastroenterology 2005;129:98-104. [PubMed: 16012939]

38. Gwee KA, Graham JC, McKendrick MW, et al. Psychometric scores and persistence of irritable bowel after infectious diarrhoea. Lancet 1996;347:150-153. [PubMed: 8544549]

39. Liebregts T, Adam B, Bredack C, et al. Immune activation in patients with irritable bowel syndrome. Gastroenterology 2007;132:913-920. [PubMed: 17383420]

40. Barbara G, Wang B, Stanghellini V, et al. Mast cell-dependent excitation of visceral-nociceptive sensory neurons in irritable bowel syndrome. Gastroenterology 2007;132:26-37. [PubMed: 17241857]

41. Guilarte M, Santos J, de Torres I, et al. Diarrhoea-predominant IBS patients show mast cell activation and hyperplasia in the jejunum. Gut 2007;56:203-209. [PubMed: 17005763]

42. Spence MJ, Moss-Morris R. The cognitive behavioural model of irritable bowel syndrome: a prospective investigation of patients with gastroenteritis. Gut 2007;56:1066-1071. [PubMed: 17324974]

43. Walker LS, Smith CA, Garber J, Claar RL. Appraisal and coping with daily stressors by pediatric patients with chronic abdominal pain. J Pediatr Psychol 2007;32:206-216. [PubMed: 16717138]

44. Kaminsky L, Robertson M, Dewey D. Psychological correlates of depression in children with recurrent abdominal pain. J Pediatr Psychol 2006;31:956-966. [PubMed: 16514051]

45. Pimentel M, Park S, Mirocha J, Kane SV, Kong Y. The effect of a nonabsorbed oral antibiotic (rifaximin) on the symptoms of the irritable bowel syndrome: a randomized trial. Ann Intern Med 2006;145:557-563. [PubMed: 17043337] 
46. Kline RM, Kline JJ, Di PJ, Barbero GJ. Enteric-coated, pH-dependent peppermint oil capsules for the treatment of irritable bowel syndrome in children. J Pediatr 2001;138:125-128. [PubMed: 11148527]

47. Bausserman M, Michail S. The use of Lactobacillus GG in irritable bowel syndrome in children: a double-blind randomized control trial. J Pediatr 2005;147:197-201. [PubMed: 16126049]

48. O'Mahony L, McCarthy J, Kelly P, et al. Lactobacillus and bifidobacterium in irritable bowel syndrome: symptom responses and relationship to cytokine profiles. Gastroenterology 2005;128:541-551. [PubMed: 15765388]

49. Whorwell PJ, Altringer L, Morel J, et al. Efficacy of an encapsulated probiotic Bifidobacterium infantis 35624 in women with irritable bowel syndrome. Am J Gastroenterol 2006;101:1581-1590. [PubMed: 16863564]

50. Tack J, Broekaert D, Fischler B, Oudenhove LV, Gevers AM, Janssens J. A controlled crossover study of the selective serotonin reuptake inhibitor citalopram in irritable bowel syndrome. Gut 2006;55:1095-1103. [PubMed: 16401691]

51. Campo JV, Perel J, Lucas A, et al. Citalopram treatment of pediatric recurrent abdominal pain and comorbid internalizing disorders: an exploratory study. J Am Acad Child Adolesc Psychiatry 2004;43:1234-1242. [PubMed: 15381890]

52. Song GH, Leng PH, Gwee KA, Moochhala SM, Ho KY. Melatonin improves abdominal pain in irritable bowel syndrome patients who have sleep disturbances: a randomised, double blind, placebo controlled study. Gut 2005;54:1402-1407. [PubMed: 15914575]

53. Morgan V, Pickens D, Gautam S, Kessler R, Mertz H. Amitriptyline reduces rectal pain related activation of the anterior cingulate cortex in patients with irritable bowel syndrome. Gut 2005;54:601-607. [PubMed: 15831901]

54. Feldman W, McGrath P, Hodgson C, Ritter H, Shipman RT. The use of dietary fiber in the management of simple, childhood, idiopathic, recurrent, abdominal pain: results in a prospective, double-blind, randomized, controlled trial. Am J Dis Child 1985;139:1216-1218. [PubMed: 2998181]

55. Chitkara DK, Rawat DJ, Talley NJ. The epidemiology of childhood recurrent abdominal pain in Western countries: a systematic review. Am J Gastroenterol 2005;100:1868-1875. [PubMed: 16086724]

56. DiLorenzo C, Youssef NN, Sigurdsson L, Scharff L, Griffiths J, Wald A. Visceral hyperalgesia in children with functional abdominal pain. J Pediatr 2001;139:838-843. [PubMed: 11743510]

57. Walker LS, Williams SE, Smith CA, Garber J, Van Slyke DA, Lipani TA. Parent attention versus distraction: impact on symptom complaints by children with and without chronic functional abdominal pain. Pain 2006;122:43-52. [PubMed: 16495006]

58. Vlieger AM, Menko-Frankenhuis C, Wolfkamp SC, Tromp E, Benninga MA. Hypnotherapy for children with functional abdominal pain or irritable bowel syndrome: a randomized controlled trial. Gastroenterology 2007;133:1430-1436. [PubMed: 17919634]

59. Hyams JS. Irritable bowel syndrome, functional dyspepsia, and functional abdominal pain syndrome. Adolesc Med Clin 2004;15:1-15. [PubMed: 15272253]

60. Abu-Arafeh I, Russell G. Cyclical vomiting syndrome in children: a population-based study. J Pediatr Gastroenterol Nutr 1995;21:454-458. [PubMed: 8583299]

61. Li BU, Balint JP. Cyclic vomiting syndrome: evolution in our understanding of a brain-gut disorder. Adv Pediatr 2000;47:117-160. [PubMed: 10959442]

62. Pfau BT, Li BU, Murray RD, Heitlinger LA, McClung HJ, Hayes JR. Differentiating cyclic from chronic vomiting patterns in children: quantitative criteria and diagnostic implications. Pediatrics 1996;97:364-368. [PubMed: 8604272]

63. Milla, PJ.; Hyman, PE.; Benninga, MA.; Davidson, GP.; Fleisher, DF.; Taminiau, J. Childhood functional gastrointestinal disorders: neonate/toddler. In: Drossman, DA.; Corazziari, E.; Delvaux, M., et al., editors. ROME III: The Functional Gastrointestinal Disorders. 3rd ed.. Allen Press; Lawrence, KS: 2006. p. 687-722.

64. Jernigan SA, Ware LM. Reversible quantitative EEG changes in a case of cyclic vomiting: evidence for migraine equivalent. Dev Med Child Neurol 1991;33:80-85. [PubMed: 1995411] 
65. Fleisher DR, Matar M. The cyclic vomiting syndrome: a report of 71 cases and literature review. J Pediatr Gastroenterol Nutr 1993;17:361-369. [PubMed: 8145089]

66. Stickler GB. Relationship between cyclic vomiting syndrome and migraine. Clin Pediatr (Phila) 2005;44:505-508. [PubMed: 16015397]

67. Withers GD, Silburn SR, Forbes DA. Precipitants and aetiology of cyclic vomiting syndrome. Acta Paediatr 1998;87:272-277. [PubMed: 9560033]

68. Li BU. Cyclic vomiting: the pattern and syndrome paradigm. J Pediatr Gastroenterol Nutr 1995;21 (suppl 1):S6-S10. [PubMed: 8708872]

69. Wang Q, Ito M, Adams K, et al. Mitochondrial DNA control region sequence variation in migraine headache and cyclic vomiting syndrome. Am J Med Genet A 2004;131:50-58. [PubMed: 15368478]

70. Andersen JM, Sugerman KS, Lockhart JR, Weinberg WA. Effective prophylactic therapy for cyclic vomiting syndrome in children using amitriptyline or cyproheptadine. Pediatrics 1997;100:977-981. [PubMed: 9374568]

71. Forbes D, Withers G. Prophylactic therapy in cyclic vomiting syndrome. J Pediatr Gastroenterol Nutr 1995;21(suppl 1):S57-S59. [PubMed: 8708871]

72. Gokhale R, Huttenlocher PR, Brady L, Kirschner BS. Use of barbiturates in the treatment of cyclic vomiting during childhood. J Pediatr Gastroenterol Nutr 1997;25:64-67. [PubMed: 9226529]

73. Andrews PL. Cyclic vomiting syndrome: timing, targets, and treatment - a basic science perspective. Dig Dis Sci 1999;44(suppl):31S-38S. [PubMed: 10490037]

74. Olson AD, Li BU. The diagnostic evaluation of children with cyclic vomiting: a cost-effectiveness assessment. J Pediatr 2002;141:724-728. [PubMed: 12410206] 
Table 1

Pediatric Rome III Criteria for Functional Disorders

\begin{tabular}{|c|c|c|c|}
\hline Functional Dyspepsia & Functional Abdominal Pain & Irritable Bowel Syndrome & Cyclic Vomiting Syndrome \\
\hline $\begin{array}{l}\text { Persistent or recurrent } \\
\text { pain } \\
\text { or discomfort } \\
\text { centered } \\
\text { in the upper } \\
\text { abdomen }\end{array}$ & $\begin{array}{l}\text { Episodic or continuous } \\
\text { abdominal pain }\end{array}$ & $\begin{array}{l}\text { Abdominal discomfort or } \\
\text { pain } \\
\text { associated with } 2 \text { or more } \\
\text { of the } \\
\text { following (see below) at } \\
\text { least } \\
25 \% \text { of the time }\end{array}$ & $\begin{array}{l}\text { Two or more periods of } \\
\text { intense nausea or retching } \\
\text { lasting hours to days }\end{array}$ \\
\hline $\begin{array}{l}\text { Criteria fulfilled at } \\
\text { least } \\
\text { once per week for at } \\
\text { least } 2 \text { months }\end{array}$ & $\begin{array}{l}\text { Criteria fulfilled at least once } \\
\text { per week for at least } \\
2 \text { months }\end{array}$ & $\begin{array}{l}\text { Criteria fulfilled at least } \\
\text { once per } \\
\text { week for at least } 2 \text { months }\end{array}$ & $\begin{array}{l}\text { Return to usual state of } \\
\text { health lasting weeks to } \\
\text { months }\end{array}$ \\
\hline $\begin{array}{l}\text { Does not meet criteria } \\
\text { for } \\
\text { irritable bowel } \\
\text { syndrome }\end{array}$ & $\begin{array}{l}\text { Functional abdominal pain } \\
\text { syndrome: includes } \\
\text { functional abdominal pain } \\
\text { at least } 25 \% \text { of the time } \\
\text { and } 1 \text { or more of the } \\
\text { following: } \\
\text { - Some loss of daily } \\
\text { functioning } \\
\text { - Additional somatic } \\
\text { symptoms such as } \\
\text { headache, limb pain, } \\
\text { or difficulty sleeping }\end{array}$ & $\begin{array}{l}\text { At least } 2 \text { of the following at } \\
\text { least } \\
25 \% \text { of the time: } \\
\text { - Pain improved with } \\
\text { defecation } \\
\text { - Pain onset associated } \\
\text { with a change } \\
\text { in stool form } \\
\text { - Pain onset associated } \\
\text { with a change } \\
\text { in stool frequency }\end{array}$ & \\
\hline
\end{tabular}

